\title{
Empirical and Automated Analysis of Web Applications
}

\author{
Prof. R. B. Kulkarni \\ Assistant Professor (Ph.D) \\ Department of CSE \\ Walchand Institute of Technology \\ Solapur University, Solapur, India
}

\author{
Prof. Dr. S. K. Dixit \\ HOD (EXTC Dept.) Ph.D. \\ Department of EXTC. \\ Walchand Institute of Technology \\ Solapur University, Solapur, India
}

\begin{abstract}
The Quality of web applications are now prima focus. As most of the transactions like e-commerce, banking and e-governance are done on the internet, having a web application to be with quality factors and secure is now the need. It has been found that aesthetic factors are decisive in deciding the quality of web application. In this paper we have surveyed various quality factors of web applications and have empirically analyzed web applications. The paper also proposes an automatic tool to calculate the quality and aesthetic factors of web application.
\end{abstract}

Keywords: Empirical Analysis, Automated Analysis, Quality Models, Web Applications.

\section{INTRODUCTION}

Web applications are becoming increasingly important, affecting almost all aspects of our daily life such as banking, retail, information gathering, entertainment and learning. Such applications are almost critical and it is very essential that such applications adhere to standards. Iwaarden et al.[1] reported $70 \%$ users leave the website if the page response exceeds 12 seconds.

Several attributes of quality web-based systems such as usability, navigation, accessibility, scalability, maintainability, compatibility and interoperability, security and reliability are not given the due consideration they deserve during development. Most web systems also lack proper testing and evaluation and design documentation.

There has been huge growth of web applications and the web applications are not just static, document oriented but dynamic applications with several technologies to form a complex, heterogeneous web systems and applications. This makes the evaluation of quality and ultimately quality assurance a tough job. It is important to improve the quality of a website, the quality of a website makes a website profitable, user friendly and accessible, and it also offers useful and reliable information, providing good design and visual appearance to meet the users' needs and expectations [2]. This can be done by defining the measurable website criteria $[3,4]$ and subsequently improving the quality of web applications.

Many of the current website evaluation methods and criteria for evaluating web application are unable to assess the performance and quality of web application, and most of them focus purely on usability and accessibility. There are still deliberations on what constitutes a good Web Applications, many detailed usability and quality guidelines have been derived, but are there is no general agreement about which web design guidelines are correct. Several research surveys have indicated that guidelines found have little consistency among them and lack of empirical validation for such guidelines.

The applications analyzed are composed of web documents (static, active or dynamic) and web objects. This paper describes a metrics suite to help define a system to measure existing web applications and to analyze its quality factors via structural properties. Nowadays the existing metrics systems for Web applications measure several structural properties, but often they measure specific web assets, such as navigation paths length, pages click-stream distances, and so on [5].

This paper aims at creation of interactive tool to evaluate web applications for empirically derived measures computed and also introduce a tool to calculate the aesthetic parameters which is a novel theme. It provides a framework for accessing quality of websites. This will show ways for developers to engineer websites and web applications in a more user-friendly way and can improve quality, usability, maintainability and navigation of web applications.

\section{EXISTING EVALUATION METHODS}

The very first conceptual work in analyzing web application was proposed by Melody Y. Ivory [6,8] in their thesis. Ivory was the first methodology to automate the metrics calculation of web application. The author's claim $63 \%$ of accuracy of the metrics tested on webby awards winning websites of year 2000. This research first followed a similar approach to highly successful work in the area of automated essay grading (Kukich [7]).

Coral et al. [9] defined web application framework to determine how the classified web metrics can be applied to improve web information access and use further they have used web metrics classification with 385 metrics using web quality model, a three-dimensional web quality model which includes Web Features Dimension, Quality Characteristics Dimension and Life-cycle Processes Dimension, they found that the triplet (usability, operation, presentation) with 149 metrics and the triplet (usability, maintenance, presentation) with 93 metrics are those with more defined metrics, and that most of the triplets that include reuse have no defined metrics. Luis et al. [10] proposed a quantitative evaluation approach to assess the quality of websites called Website Quality Evaluation Method (WebQEM). In order to evaluate, compare, and rank the quality of Websites, Luis Olsina applies a set of activities regarding the proposed methodology. Their primary goal is to classify and group the single elements which are then placed into four major categories, namely usability, functionability, site reliability and efficiency. We further classify analysis into different factors as follows. 


\subsection{Quantitative Analysis Tools}

There are many quantitative methods for evaluating Web sites which focus on statistical analysis of usage patterns in server logs. Traffic based analysis which include page per visitor and time-based analysis which include click paths and page-view durations that provide data which the evaluator must interpret to identify usability problems. This analysis is largely inconclusive. Other techniques compare quantitative Web page measures - such as the number of links or graphics - to thresholds. Log analysis research falls into two categories; papers that relate findings [11],[12] and papers that suggest more efficient and meaningful methods for analyzing logs.

\subsection{Simulation Tools}

Simulation has also been used for Web site evaluation. For example, WebCriteria's [14] Site Profile (www.webcriteria.com) attempts to mimic a user's information-seeking behavior within an implemented site model. This tool uses an idealized user model that follows an explicit, pre-specified navigation path through the site and estimates several metrics, such as page load and optimal navigation times.Chi, Pirolli, and Pitkow [13,15] have developed a simulation approach for generating a site's navigation paths based on content similarity, server log data, and linking structure. The simulation models users traversing the site from specified start pages, using information scent to make navigation decisions. The above approaches do not account for the impact of various Web page attributes, such as text amount or link layout.

\subsection{Guideline Review Tools}

There are several tools available. One of the oldest available is Bobby (www.cast.org/bobby/), from the Center for Applied Special Technology [16] for validating Web pages in terms of accessibility by users with disabilities such as color-blindness. A similar analysis technique, the Design Advisor, uses heuristics about the effects of various elements, such as motion, size, images, and color, to determine and superimpose a scanning path on a Web page. The heuristics are based on empirical results from eye-tracking studies of multimedia presentations. They have not been validated for Web pages. There are several tools which can be referred in the contemporary situation. However an API from Google (www.code.google.com/speed/pss) which checks the speed of web application, also tool from Pingdom which checks the response time of web applications.

\subsection{HTML Best Practice Checkers}

HTML best practices checkers are some of early tools to be produced were automated checklists that validated a Web page against a set of generally accepted HTML 'best practices', reporting any non-compliances. There are several tools available like The National Institute of Standards and Technology [17] which offers a free set of utilities under the WebMetrics suite, and a comparable tool is commercially marketed by UsableNet [18] named LIFT. W3C offers HTML validation services for the newer web application. There is constant growth of such services available on the net.

\section{WEB APPLICATION QUALITY MODELS}

Web technologies and application are becoming important in information system world. The main problem of web development is short span of window due to ever changing world which can result in quality comprise. A good mechanism for controlling quality of web based application is use of web metrics. Due to exponential growth of web there is need for newer metrics that may provide deeper impact on the web as a whole and on individual sites from different perspective. One of the most important motivations for deriving such metrics is improving the quality of web application. Looking at different aspects and research world, we zeroed on ISO 9126 factors and also proposed two new metrics aesthetics and credibility. The site quality (or Quality of Web Applications) could be measured from two perspectives: Programmers, and End-users [19]. The aspects of website quality from programmers focus on the degree of Maintainability, Security, Functionality, etc. Whilst the end-users are interested in Usability, Efficiency, Creditability, Security issues.

Expanding these concepts, the usages of website quality may depend on -

1. Task-related factors which have an impact on end users for presentation quality and content.

2. Performance-related factors which are related to the efficiency and technologies of web applications, for example response time, transaction output and reliability.

3. Development-related factors that are crucial for developers and maintainers of a web application.

So, as per our study process we are defining web quality parameters which can be implemented as a tool to provide a comprehensive results. The need to have comprehensive model leads us to come to conclusion for selecting quality model for assessment of web applications.

\section{EXISTING WEBSITE QUALITY MODELS \\ 4.1 ISO Quality Model}

In recent years, several experts have worked on different proposals to improve this website quality model, including methodologies [20], quality frameworks [21] estimation models [22],[23] criteria [24], usability guidelines [25], metrics [26],[27] and web evaluation tool [28]. We look at

\begin{tabular}{|c|c|c|}
\hline \multirow{8}{*}{$\begin{array}{l}\text { Web } \\
\text { Application } \\
\text { Quality }\end{array}$} & Functionality & $\begin{array}{l}\text { Suitability Accuracy, } \\
\text { Interoperability } \\
\text { Compliance }\end{array}$ \\
\hline & Usability & $\begin{array}{l}\text { Ease of use, } \\
\text { comprehensibility, } \\
\text { level of } \\
\text { communication }\end{array}$ \\
\hline & Reliability & $\begin{array}{l}\text { Maturity, Fault } \\
\text { - Tolerance, } \\
\text { Recoverability }\end{array}$ \\
\hline & Efficiency & $\begin{array}{l}\text { Time behavior, } \\
\text { Resource behavior }\end{array}$ \\
\hline & Maintainability & $\begin{array}{l}\text { Analyzability, } \\
\text { Changeability, } \\
\text { Stability }\end{array}$ \\
\hline & Aesthetic & $\begin{array}{l}\text { Layout balance, Color } \\
\text { balance, Economy } \\
\text { Harmony }\end{array}$ \\
\hline & Credibility & $\begin{array}{l}\text { Legality, Privacy, } \\
\text { - Security, } \\
\text { Transparency }\end{array}$ \\
\hline & Portability & $\begin{array}{l}\text { Adaptability, } \\
\text { Installability, } \\
\text { Conformance, } \\
\text { Replaceability }\end{array}$ \\
\hline
\end{tabular}

Figure 1 : Characteristics and sub characteristics of the ISO 9126 quality model with two additional characteristics 
Several qualities have been proposed in the literature, each with their own set of characteristics and sub-characteristics. However, most of those characteristics is good exception is [29] are not geared to automatic collection and classification. On the other hand, software engineering has a widely adopted quality model, the ISO/IEC 9126 [30], and several researchers in web engineering have adopted it as a basis for their quality models. We will do likewise, by keeping the existing top characteristics.

The quality model is based on the ISO 9126 standard [31]. The model is represented by hierarchical three-level tree structure and consists of six top-level characteristics from the ISO model: functionality, usability, reliability, efficiency, maintainability and portability. The characteristics of functionality, usability, reliability and efficiency have the most impact on users' perception of the quality, while maintainability and portability are mostly visible from the administrators' perspective.

There is need to study quality aspects (quality model) which will be the leading factor in achieving website success and will apply to the majority of current live websites. From previous research, the quality website is developed from quality of software. Gerald Weinberg [32] defined that the quality of software as inherently subjective and different people who will experience different quality even in the same software. It can also apply in a website which means measuring user satisfaction is more important than anything. A web application is just like software (i.e. it applies to some entity, or some prototype, or its information architecture) defined in terms of a system of attributes, e.g. readability or coupling. Finally an assessment of the attributes that is a certain product possesses.

These aspects taken together are called the Quality Model [33].Generally the website quality is prone to subjective interpretations unless it is quantified by a web quality model. A web quality model needs to define website quality requirements which are identified by a set of measurable attributes and meet the users' expectations. In other words, to evaluate the quality of website, the appropriate metrics have to be defined. Nevertheless the quality assurance process became the challenges for the new discipline of website application. There were a number of experts or organizations who researched on different proposals to improve website quality, including quality frameworks, criteria, evaluation methodologies, approaches and metrics. In fact, since the website quality process became a particularly valuable topic which is ongoing and commercially researched, especially in website quality metrics. A set of metrics has been proposed for quantifying website quality attributes since the 1990s [34], [35]. As quality of website is an important aspect and has valuable background. But the big question of quality of websites is still being poor and is cause of dissatisfaction in user is major drawbacks and needs to be study [36], [37].

To address quality aspects two more metrics aesthetics and credibility have been added to identify the web application into good or bad. Research carried out by Stanford university [38] shows the design and looks are most important aspect with $46.1 \%$, then the structure carries $28.5 \%$ and information focused $25.1 \%$. Aesthetics parameters have been using segmentation algorithm. It is the first of its kind as the earlier aesthetics parameters were drawn on empirical studies and not as practical software. Segmentation algorithm is used to draw various factors of aesthetics.

- Functionality is the capability of the Web site to provide functions and properties which meet stated and implied needs when the site is used under specified conditions.

- Usability is the capability of the Web site to be understood, learned and liked by the user, when used under specified conditions.

- Reliability is the capability of the site to maintain a specified level of performance when used under specified conditions. The sub characteristics are availability, fault tolerance and security.

- Efficiency is the capability of the site to provide appropriate performance, relative to the amount of resources used, under stated conditions.

- Maintainability is the capability of the site to be modified. Modifications may include corrections, improvements or adaptation of the site to changes in environment, and in requirements and functional specifications. Sub characteristics are analyzability and changeability.

- Portability is the capability of the site to be transferred from one environment to another. This characteristic is further decomposed into sub characteristics adaptability, installability and coexistence.

- Aesthetic is the broader concept of user experience which includes usability, beauty and overall quality and hedonic. The aesthetics of web page design is a crucial but until recently, somewhat neglected area of empirical investigation. The visual impact of a web page can have a significant influence on user experience and has important implications for effective communication.

- Credibility is a factor to check the trust worthiness of web application. It also checks for evidence of quality control, known or respective authority, organizational support and authoritative source. The source that supplies some good evidence that allows you to trust it.

\section{EMPIRICAL ANALYSIS OF WEB SYSTEMS AND APPLICATIONS}

Empirical analysis is used to analyze web applications. There are different methods and techniques to test web application's quality. These methods and techniques can be divided into evaluation with user participation including web surveys, focus groups, thinking aloud etc. and evaluation without user. Without users include identifying quality problems by checking a set of broad quality guidelines, expert based methods, guideline checking and automated tools. Both methods for checking quality of web application are used. A questionnaire is administered through the web. This method allows us to test quality of web application in a systematic way with help of actual users. The factors gained from applying this method were tested by reapplying the same method to verify their validity. The main motivation behind the study is to promote web quality and try to strike a balance of quality factors and aesthetic and credibility factors. The main advantage of this method is that a quality questionnaire gives you feedback from the user's perception. This method is easy to administrate enables the experimenter. It is valuable for summative evaluation and comparatively easy to analyze.

\subsection{Evaluating the web interface}

This section discusses a study conducted to determine to know various aspects of web applications that affect or the user is concerned so that it would be possible to find out whether the site is good or bad. The metrics chosen are based on different 
research papers and given for analysis. The study also demonstrates that such exercises do help in knowing the situation

\subsection{Study Design}

The study was conducted in two years phases with final year graduate students of Computer Science and Engineering for the year 2010 and 2011. Approx. 78 participants took part in the analysis where they completed two questionnaires pertaining to 1200 web applications.

\subsection{Study Site}

The study site was not fixed and varied to the department's research laboratory or student's own machines. The site crawler tool written by us and tool Wget was used to download the pages.

\subsection{Participants}

Study participants were final year undergraduate students of Walchand Institute of Technology, an engineering college at Solapur. Students had an exposure on the web application and $\mathrm{HCI}$ course in the first term. In the first stage of data collection, A questionnaire consisting of 70 questions was given to students enrolled for the study. All of the students in the sample were 18 to 20 years age and approximately $56 \%$ of males and $44 \%$ females. The goal was to examine quality, aesthetics and credibility factors of web applications. Before completing the questionnaire the users were instructed on how to navigate web application and these factors were explained to them. To verify and validate the data we use same web applications for two years and new database for each year was given. Surprisingly the results of the two years do not show much difference except the parameters in security, visual and aesthetic parameters have increased. There has been also not much change in social networking factors.

\begin{tabular}{|c|c|c|c|}
\hline \multirow{2}{*}{$\begin{array}{l}\text { Sr. } \\
\text { No. }\end{array}$} & \multirow[t]{2}{*}{ Parameters } & 2010 & 2011 \\
\hline & & $\begin{array}{c}\text { Factor } \\
1\end{array}$ & Factor 1 \\
\hline 1 & $\begin{array}{l}\text { Is the website aesthetically } \\
\text { pleasing? }\end{array}$ & 5.21 & 5.67 \\
\hline 2 & $\begin{array}{l}\text { Does it create meaningful visual } \\
\text { interest? }\end{array}$ & 4.42 & 4.56 \\
\hline 3 & $\begin{array}{l}\text { Is it visually suitable for its } \\
\text { purpose? }\end{array}$ & 4.49 & 5.30 \\
\hline 4 & Is the color choice appropriate? & 4.13 & 4.50 \\
\hline 5 & $\begin{array}{l}\text { Is the website designed to } \\
\text { appeal? }\end{array}$ & 3.92 & 4.01 \\
\hline 6 & $\begin{array}{l}\text { Does the website use consistent } \\
\text { elements and appropriate } \\
\text { graphics and images? }\end{array}$ & 4.33 & 4.45 \\
\hline
\end{tabular}

\section{Table 1 : Preliminary Results of analysis of design of web application}

It is evident from Table 1 that about the design aspects of web applications of Indian origin. The survey marks aesthetics parameters and visually suitable parameters to be somewhat equal. The color choice and design to appeal factors having ranking less than 5 . The color choice in Indian web application have been found myriad with color orange being very popular among the web applications.

\begin{tabular}{|c|l|c|c|}
\hline $\begin{array}{c}\text { Sr. } \\
\text { No. }\end{array}$ & \multicolumn{1}{|c|}{ Parameters } & 2010 & 2011 \\
\cline { 3 - 4 } & $\begin{array}{c}\text { Factor } \\
1\end{array}$ & Factor 1 \\
\hline 1 & $\begin{array}{l}\text { Does the website make use of } \\
\text { "white space"? }\end{array}$ & 4.59 & 5.51 \\
\hline 2 & $\begin{array}{l}\text { Are the size and style of fonts } \\
\text { appropriate? }\end{array}$ & 4.35 & 4.80 \\
\hline 3 & $\begin{array}{l}\text { General layout of the page and } \\
\text { alignment use visual design } \\
\text { techniques to appear uncluttered }\end{array}$ & 3.93 & 3.98 \\
\hline
\end{tabular}

Table 2 : Preliminary results of analysis of typography of web application

It is evident from Table 2 that typography or fonts used on sites not very contemporary. There is no experimentation of fonts or calligraphy on web application mostly Arial, San-serif are perceived fonts used.

\begin{tabular}{|c|c|c|c|}
\hline \multirow{2}{*}{$\begin{array}{l}\text { Sr. } \\
\text { No. }\end{array}$} & \multirow{2}{*}{ Parameters } & 2010 & 2011 \\
\hline & & Factor 1 & Factor 1 \\
\hline 1 & $\begin{array}{l}\text { Is the current written in clear } \\
\text { and simple terms }\end{array}$ & 4.51 & 5.13 \\
\hline 2 & $\begin{array}{l}\text { Is the amount of content on } \\
\text { each page appropriate? This } \\
\text { means the content not being too } \\
\text { wordy }\end{array}$ & 3.47 & 3.83 \\
\hline 3 & $\begin{array}{l}\text { Is the language and tone of the } \\
\text { working natural and familiar to } \\
\text { the website's target market? }\end{array}$ & 4.52 & 5.03 \\
\hline 4 & Is the content informative? & 5.11 & 5.57 \\
\hline 5 & $\begin{array}{l}\text { Are keywords and key phrases } \\
\text { used in a balanced way } \\
\text { throughout the content? }\end{array}$ & 3.97 & 4.03 \\
\hline 6 & $\begin{array}{l}\text { Is there limited use } \\
\text { unnecessary } \\
\text { acronyms? }\end{array}$ & 4.92 & 4.98 \\
\hline 7 & $\begin{array}{l}\text { Are appropriate policies } \\
\text { included e.g. customer } \\
\text { satisfaction guarantee, returns, } \\
\text { security, privacy and copyright } \\
\text { easy to understand? }\end{array}$ & 5.53 & 6.12 \\
\hline
\end{tabular}

Table 3 : Preliminary results of analysis of content of web application

It is evident that from table 3 that informative content on web application is better than other factors like clarity and language and there is control on limited use of jargons in the web application.

\begin{tabular}{|c|l|c|c|}
\hline $\begin{array}{c}\text { Sr. } \\
\text { No. }\end{array}$ & \multicolumn{1}{|c|}{ Parameters } & 2010 & 2011 \\
\cline { 2 - 4 } & $\begin{array}{l}\text { Factor 1 } \\
\text { Is the content structured to find } \\
\text { information easily? }\end{array}$ & 5.14 & 5.60 \\
\hline 2 & $\begin{array}{l}\text { Is the content mark-up } \\
\text { appropriately? }\end{array}$ & 4.93 & 5.14 \\
\hline 3 & $\begin{array}{l}\text { Are headings obvious and } \\
\text { descriptive? }\end{array}$ & 4.31 & 4.74 \\
\hline 4 & $\begin{array}{l}\text { Does the website have clear, } \\
\text { predictable navigation with } \\
\text { uncomplicated structure? }\end{array}$ & 5.13 & 5.55 \\
\hline 5 & $\begin{array}{l}\text { Are internal links managed } \\
\text { well? Is there is site map or } \\
\text { search facilities where } \\
\text { appropriate? }\end{array}$ & 5.84 & 5.91 \\
\hline 6 & $\begin{array}{l}\text { Are menu groupings logical and } \\
\text { easy to follow? }\end{array}$ & 6.32 & 6.56 \\
\hline
\end{tabular}

Table 4 : Preliminary results of analysis of Information Architecture of web application 
It if evident that from table 4 architecture of web application shows that content markup is appropriate to some extent while navigation is also Ok but not up to the mark.

\begin{tabular}{|c|l|c|c|}
\hline \multirow{2}{*}{$\begin{array}{c}\text { Sr. } \\
\text { No. }\end{array}$} & \multicolumn{1}{|c|}{ Parameters } & 2010 & 2011 \\
\cline { 3 - 4 } & \multicolumn{2}{|c|}{ Factor 1 } & Factor 1 \\
\hline & Ratings (0 to 10) [0 - least,10-highest] \\
\hline & Aesthetics & 5.94 & 6.01 \\
\hline & Efficiency & 4.51 & 4.93 \\
\hline & Portability & 3.85 & 4.23 \\
\hline & Functionality & 5.31 & 5.56 \\
\hline & Usability & 5.54 & 5.69 \\
\hline & Performance & 4.93 & 5.12 \\
\hline & Security & 4.32 & 4.95 \\
\hline & Reliability & 4.96 & 5.12 \\
\hline & Maintainability & 3.93 & 4.11 \\
\hline
\end{tabular}

Table 5 : Preliminary results of analysis of Quality Parameters of web application

The survey results of web application as per table 5 indicate the overall quality factors of web application under study. It shows usability ranking high where as maintainability on lower criteria.

\begin{tabular}{|c|c|c|c|}
\hline \multirow{2}{*}{$\begin{array}{l}\text { Sr. } \\
\text { No. }\end{array}$} & \multirow[t]{2}{*}{ Parameters } & 2010 & 2011 \\
\hline & & Factor 1 & Factor 1 \\
\hline 1 & \multicolumn{3}{|l|}{ Check for presence $(\mathrm{Y} / \mathrm{N})$} \\
\hline & Site map & 5.38 & 5.76 \\
\hline & Search tools & 5.14 & 5.74 \\
\hline & Contact us & 6.32 & 6.73 \\
\hline & FAQ & 3.94 & 4.30 \\
\hline & About us & 4.74 & 4.93 \\
\hline & Date of updates & 3.51 & 3.72 \\
\hline 2 & General layout & 5.93 & 5.97 \\
\hline 3 & Information conveyed & 4.61 & 4.75 \\
\hline 4 & Content & 4.91 & 5.10 \\
\hline 5 & Look, feel, aesthetic & 5.31 & 5.72 \\
\hline
\end{tabular}

Table 6 : Preliminary results of analysis of essential web metrics of web application

The survey was concentrated to find the essential parameters which are there on web application. However the web applications have poor identity about different web factors required to be on web application. The site map and contact us scores higher than any other parameters.

\begin{tabular}{|c|l|c|c|}
\hline \multirow{2}{*}{$\begin{array}{c}\text { Sr. } \\
\text { No. }\end{array}$} & \multicolumn{1}{|c|}{ Parameters } & Yes \% & Yes \% \\
\cline { 3 - 4 } & & Factor 1 & Factor 1 \\
\hline 1 & RSS feeds & 4.42 & 3.59 \\
\hline 2 & Twitter & 2.75 & 3.35 \\
\hline 3 & Blog & 2.98 & 3.66 \\
\hline 4 & facebook & 3.92 & 5.52 \\
\hline 5 & Social networking site & 2.99 & 3.80 \\
\hline 6 & Videos, photos & 6.41 & 6.32 \\
\hline 7 & Podcast & 1.16 & 2.53 \\
\hline 8 & Widgets & 2.14 & 3.93 \\
\hline 9 & Poll & 3.52 & 1.42 \\
\hline 10 & Technorati & 0.83 & 0.89 \\
\hline 11 & Delicious & 1.13 & 1.62 \\
\hline 12 & Stumble upon & 0.94 & 0.97 \\
\hline 13 & Mixx & 1.33 & 1.59 \\
\hline
\end{tabular}

Table 7 : Preliminary results of social networking and web 2.0 of web application

Social networking fairs with not many web applications having web 2.0 or social networking features on web application. There is very slow usage or many web applications not upgraded their web applications to social networking factor.
The usage of videos and photos is more and lot of web applications are hosting flash where as migration from old legacy web application to flash based web application the major change is only a flash module which is added to web application, where as old web application is retained as it is.

The credibility survey was done with view to find credibility of web application and to find out how reliable web applications are. The survey indicates majority of web applications have authentication and contact us details which gives presumption that the site owners are accessible and can be reached out There are several other factors to check credibility of web applications. We however have restricted to the contact details only.

After having considered the empirical analysis of web applications we needed to authenticate the work and to look at web applications at different perspective and to generate accurate results we took up the work of automated analysis of web applications. The next section deals with the development of analysis framework, metric evaluation and a tool which automatically calculates the quality factors based on ISO 9126 and other web quality factors which include few of essential factors to make a web application having quality factors checked. We also have automated tools to find aesthetic and credibility factors which is novel.

\section{AUTOMATED ANALYSIS}

An automatic evaluation method is one where software is used to evaluate a web application. The tool plays a major role to evaluate web application for quality. It helps to find certain types of design anomalies, page loading, missing links, use of jargon, accessibility problems. Several automated tools have been developed few are commercial and open source as well. EvalAccess 2.0 [1], Cynthia Says Portal [2], Truwex website QA tool [3] and few others.

A quality framework has been proposed which automatically calculates the factors defined in ISO 9126 quality factor parameters and other quality factors which include the different web metrics which are not part of quality factors but are essential factors for validation of web application to be of quality. The tool also has been used to compute aesthetic and credibility factors automatically by parsing the web application under study. The metric computation toll designed is a used to sum up all these valuations to generate the results. The results indicate whether the web application is good or bad.

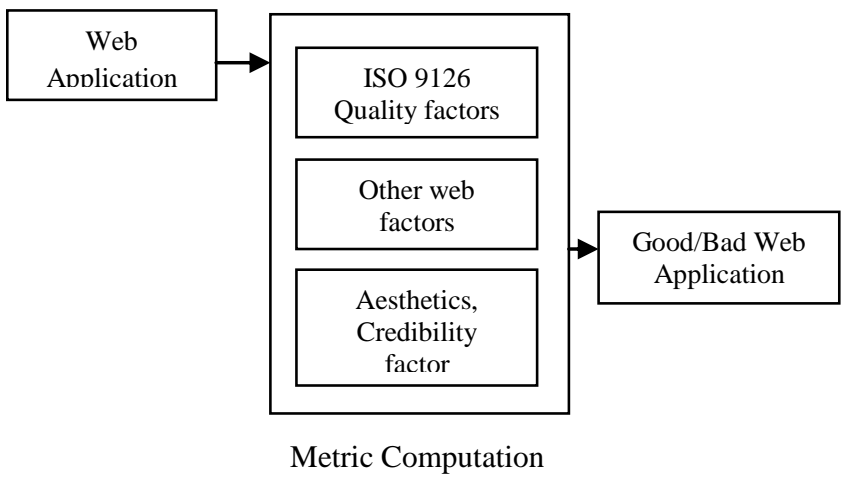

Figure 2. Metrics Computation Tool

In this approach, there are three different processes carried out which calculates the values generated each level and final score leads to quality factor of web application. The described Web 
site quality model follows the principles stated in the ISO 9126 standard. The evaluation process distinguishes four stages: definition of quality requirements, definition of metrics, evaluation planning and preparation and evaluation execution. This process can be applied during any phase of the Web site lifecycle.

\section{- Methodology}

The Metrics tool computes more than 50 page and site level metrics. The parsing tool generates a report of the web application which is under consideration. The Parser used is based on Jericho Html parser to the component for assessing the quality of web design gives detailed information of the site structure and the various factors which are taken as a reference of quality aspects of ISO 9126. The study reported preliminary collection of $100 \mathrm{web}$ applications. Each page corresponds to a site that has been highly rated by experts or has no rating. We derived the expertise rating from PC Magazine, Top Hundred and Webby awards. For each page we computed metrics having to do with layout, page composition, structure, size, links and colors.

\section{- Web Application Evaluation Framework}

The description of the framework on the basis of the categories and dimensions of the quality factors is given in the following table. It also shows the relevancy of each category to the phases and sub-phases of a quality framework. The proposed attributes help to evaluate each phase.

It is necessary to effectively classify the quality characteristics in WEF that should be compatible to different domains of web applications. It is very important because the main aim of the study is to evaluate web applications automatically with WebAna tool regardless of domain types and language of design. There are more than 40 measurable quality metrics and web metrics added to calculate strength of web applications to differentiate the web applications into good or bad.

\section{CASE STUDY}

We have taken case study of one of the axis bank (www.axisbank.com) for evaluation purpose; it is the official leading Private Sector Bank in India. The site was chosen randomly for the evaluation purpose. Tool has been run for quality factors, other web factors and aesthetics to generate several reports about the web application.

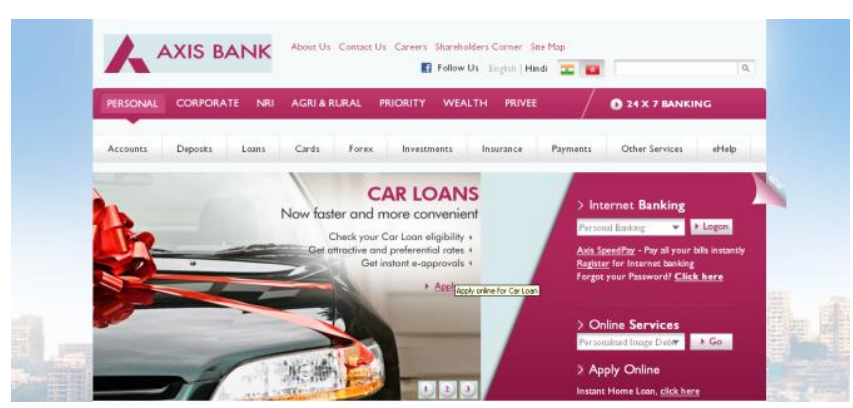

Figure 3 : Screenshot of web application www.axisbank.com under study

In this approach, three different processes are carried out which calculates the values generated each level and final score leads to quality factor of web application. The described Web site quality model follows the principles stated in the ISO 9126 standard. The evaluation process distinguishes four stages: definition of quality requirements, definition of metrics, evaluation planning and preparation and evaluation execution This process can be applied during any phase of the Web site lifecycle.

The screen shown below is of calculation of several quality factors of web application. The factors are taken from different sources and are as per ISO 9126 quality, characteristics and sub-characteristics. The tool calculates the value assigned to each factor and gives total of quality factors applied to it.

The second screen generates output of the marks generated for factors other than factors already computed. The factors are added as a sum along with quality factors and aesthetics factors go generate a count which gives enough evidence to prove whether site is good or bad. Subsequently it generates graph along with ISO 9126 quality factors.

\begin{tabular}{|l|c|l|c|l|l|}
\hline Metrics & $\begin{array}{l}\text { Quality } \\
\text { Character } \\
\text {-istics }\end{array}$ & $\begin{array}{l}\text { Other } \\
\text { web } \\
\text { factor } \\
\text { s }\end{array}$ & $\begin{array}{l}\text { Aestheti } \\
\text { c factors }\end{array}$ & $\begin{array}{l}\text { Credibilit } \\
\text { y }\end{array}$ & $\begin{array}{l}\text { Final } \\
\text { Scor } \\
\text { e }\end{array}$ \\
\cline { 2 - 5 } & $50 \%$ & $30 \%$ & $20 \%$ & \\
\hline $\begin{array}{l}\text { axisbank.co } \\
\mathrm{m}\end{array}$ & 28.00 & 16.80 & 11.2 & 56 \\
\hline
\end{tabular}

Table 8 : Results of web application axisbank.com calculated by automated analysis

\section{- Overall Evaluation}

The tool has been tested for automated analysis of quality factors, other web factors and aesthetic and credibility factors and generated output is given below. The results above 40 count are considered as good sites where as count 25 and below are considered to be bad web application. The empirical analysis results and automated results match. There is a small incremental difference in the result which can be ignored. With this experimentation we tend to prove that our empirical and automated results give correct perspective of web application and show whether the web application is good or bad.

According to the formulae which has been mentioned the total characteristics are calculated.

\begin{tabular}{|l|c|c|c|c|c|}
\hline Web Application & $\begin{array}{l}\text { Quality } \\
\text { Character- } \\
\text { istics }\end{array}$ & $\begin{array}{l}\text { Other } \\
\text { web } \\
\text { factors }\end{array}$ & $\begin{array}{l}\text { Aesthetic } \\
\text { factors }\end{array}$ & Credibility & $\begin{array}{c}\text { Final } \\
\text { Score }\end{array}$ \\
\cline { 2 - 6 } & $50 \%$ & $30 \%$ & \multicolumn{2}{|c|}{$20 \%$} & \\
\hline bharatstudent.com & 24 & 14.4 & 9.6 & $\begin{array}{c}48 \\
\text { (Good) }\end{array}$ \\
\hline gati.com & 20 & 12 & 8 & $\begin{array}{c}40 \\
\text { (Good) }\end{array}$ \\
\hline iitb.ac.in & 22.5 & 13.5 & 9 & $\begin{array}{c}45 \\
\text { (Good) }\end{array}$ \\
\hline iimahd.ernet.in & 24 & 14.4 & 9.6 & $\begin{array}{c}48 \\
\text { (Good) }\end{array}$ \\
\hline isb.edu & 22 & 13.6 & 6.4 & $\begin{array}{c}42 \\
\text { (Good) }\end{array}$ \\
\hline balajiwafers.com & 12.5 & 7.5 & 5 & $\begin{array}{c}25 \\
\text { (Bad) }\end{array}$ \\
\hline zpsolapur.gov.in & 7.9 & 4.74 & 3.16 & $\begin{array}{c}15.8 \\
\text { (Bad) }\end{array}$ \\
\hline msbhsc.ac.in & 11.5 & 6.9 & 4.6 & $\begin{array}{c}23 \\
\text { (Bad) }\end{array}$ \\
\hline nss.nic.in & 11.5 & 6.9 & 4.6 & $\begin{array}{c}23 \\
\text { (Bad) }\end{array}$ \\
\hline kamatyatri.in & 10.5 & 6.3 & & $\begin{array}{c}21 \\
\text { (Bad) }\end{array}$ \\
\hline
\end{tabular}

Table 9 : Results of overall evaluation of results calculated by automated tool 


\section{CONCLUSION}

This paper presented an analysis methodology consistent with measurement approaches used in the performance evaluation domain and guideline review approaches used in the quality evaluation domain.

\section{- Empirical Analysis}

The survey was intended to get idea of real world applications and their different aspects of design, layout, typography which is consistent to our predefined ISO 9126 quality models. The survey was carried on 1200 web applications for two years 2010 and 2011. The quality research which was done earlier was focused on general descriptions and was not focused on aspects that are required. In this study, we have moved beyond descriptive evidence to empirical evaluation and verification by developing a multi-dimensional quality factors based on ISO 9126. The results of the questionnaire uncovered four factors to be determinant. The factors are content, navigation, security and presentation. Aesthetic factor scored on higher than other factors. Security is also dominant factor in all these. Limitations of the study include those customarily associated with instrument building and survey methods. The web quality model has practical as well as theoretical research applications. In terms of practical applications a validated tool provides an important aspect for accessing the quality of web application.

\section{- Automated Analysis}

In recent initiatives of web research communities, web metrics specifications and catalogue environment as technological support for quality assessment has been neglected. As a way to contribute we have developed an interactive tool to enable non-professional website builders to check for quality aspects and also generate discrepancy report of web application under consideration. The approach intends computation of more than 110 quantitative metrics to assess the web applications features. We have added two quality factors aesthetic and credibility to ISO 9126 though credibility is the part of ISO 9126 quality factors, we have shown it as different factor to endorse the importance of aesthetic factors. The first time we have used novel method to calculate aesthetic factor using segmentation algorithm. We have tested the tool which generates precise results for the web application under study.

The proposed quality model can be useful not only as a frame of reference to evaluate existing sites and fix errors but also can be helpful in improving their quality through reengineering. Data collected can support maintenance.

\section{REFERENCES}

[1] - Iwaarden J.V., Wiele T.V.D., Ball, L., and Millen, R. (2003), Applying SERVQUAL to Web sites : an exploratory study, International Journal of Quality and Reliability Management, 20 (8), pp. 919-935.

[2] J. Hartmann, A. D. Angeli and A. Sutcliffe, "Framing the User Experience: Information Biases on Website Quality Judgement", Proceeding of the Twenty-sixth Annual SIGCHI Conference on Human Factors in Computing Systems, Florence, Italy, April 2008, pp 855-864.
[3] G. Gledec, "Quality Model for the World Wide Web", in 8th International Conference on Telecommunications ConTEL2005 Zagreb, Croatia, June 2005, pp 281-287.

[4] Z. Zhou, H. Zhou, and H. Yang, "Evaluating Websites using A Practical Quality Model", in 14th International Conference on Automation \&Computing Society West London, England, September 2008.

[5] - Dhyani J., Keong W. and Bhowmick S, A Survey of Web Metrics, ACM Computing Surveys, 2002

[6] - M. Y. Ivory and M. Hearst, "The State-of-The-Art in Automating Usability Evaluation of User Interfaces", in ACM Computing Surveys, July 2001.

[7] - Kukich, K. (2000). The debate on automated essay grading. IEEE Intelligent Systems, 15(5), 22-27.

[8] - Ivory, M. Y., Sinha, R. R., and Hearst, M. A. (2000a). Preliminary findings on quantitative measures for distinguishing highly rated information-centric web pages. In Proceedings of the 6th Annual Conference on Human Factors and the Web, pages 214\{228. Available from http://www.tri.sbc.com/hfweb/.

[9]- C. Calero, J. Ruiz and M. Piattini, "Classifying Web Metrics Using the Web Quality Model", in Online Information Review, April 2005, pp 227-248.

[10] - Luis Olsina1, Gustavo Rossi, (2003), A Quantitative Method for Quality Evaluation of Web Sites and Applications

[11] - Cockburn, A. and McKenzie, B. (2000). What do web users do? an empirical analysis of web use. Technical report, University of Canterbury, New Zealand.

[12] - Miller, C. S. and Remington, R. W. (2000). A computational model of web navigation: Exploring interactions between hierarchical depth and link ambiguity. In Proceedings of the 6th Annual Conference on Human Factors and the Web. Available from http://www.tri.sbc.com/hfweb/

[13] - Chi, E.H., Pirolli, P. and Pitkow J. (2000), The scene of a site : A system for analyzing and predicting information scrent, usage and usability of a web site. In Proceedings of ACM CHI '00 Conference on Human Factors in Computing Systems. Available from http://citseer.nj.nec.com/chi00scent.html.

[14] - WebCriteria (1999). Max, and the objective measurement of web sites. Technical report, WebCriteria Inc.

[15] - Chi, E. H., Pirolli, P., and Pitkow, J. (2000). The scent of a site: A system for analyzing and predicting information scent, usage and usability of a web site. In Proceedings of ACM CHI '00 Conference on Human Factors in Computing Systems. Available from http://citeseer.nj.nec.com/chi00scent.html.

[16] - Center for Applied Special Technology (2001). Welcome to Bobby 3.2. Online. URL http://www.cast.org/bobby/

[17] - National Institute of Standards and Technology (2001). Web metrics testbed. Online. URL http://zing.ncsl.nist.gov/WebTools/.

[18] - UsableNet (2001). LIFT online. Online. URL http://www.usablenet.com/lift online/index.htm. 
[19] - B. Liburne, P. Devkota and K. M. Khan, "Measuring Quality Metrics for Web Applications", in 2004 IRMA International Conference, New Orleans, USA, August 2004.

[20] - N. Bevan, "Quality in Use: Meeting User Needs for Quality", Journal of Systems and Software, vol. 49, December 1999, pp 89-96.

[21] - G. Brajnik, "Towards Valid Quality Models for Websites", in 7th Conference onHuman Factors and the Web, Madison, Wisconsin, June 2001.

[21] - B. Yen, P. Jen-Hwa Hu and M. Wang, "An analytical Approach for Effective Website Design: A Framework for Modelling, Evaluation and Enhancement", Publisher Elsevier Science Publishers B.

[22] Z. Li, J. Li and X. Li, "A Study on Website Operation Efficiency Evaluation: Based on DEA Model", in Management and Service Science (MASS '09), also in International Conference on, Sept 2009, pp $1-6$

[23] L. Mich, M. Franch and L. Gaio, "Evaluating and Designing Website Quality", vol. 10: The IEEE Computer Society, March 2003, pp 34-43.

[24] - W3C, "W3C Quality Assurance", July 2006.

[25] - J. Nantel and E. Glaser, "The Impact of Language and Culture on Perceived Website Usability", Publisher Elsevier Science Publishers B. V. Amsterdam, The Netherlands, March 2008, pp 112-122.

[26]- Fogg, B.J. 2003. Prominence-interpretation theory: explaining how people assess credibility online. In Proceedings of CHI '03 extended abstracts on Human Factors in Computing Systems (Florida, USA, April 05 10, 2003). ACM Press, New York, NY, 722-723.

[27] - J. Nielsen, Usability Engineering Morgan Kaufmann, September 1993.

[28] - H. Jati and D. Durai Dominic, "Quality Evaluation of Egovernment Website Using Web Diagnostic Tools: Asian
Case", in Proceedings of the 2009 International Conference on Information Management and Engineering, Publisher IEEE Computer Society Washington, DC, USA, Sept 2009, pp 85-89.

[29] - C. Calero, J. Ruiz and M. Piattini, "Classifying Web Metrics Using the Web Quality Model", in Online Information Review, April 2005, pp 227-248.

[30] - ISO (9241-151) 2008 Ergonomics of human-system interaction-Part 151: Guidance on World Wide Web user interface. BSI -British Standards.

[31] Arnheim, R. 1983 Art and visual perception: A psychology of the creative eye. Los Angeles, University of California Press.

[32] G. M. Weinberg, Quality Software Management: Anticipating Change Dorset House Publishing Co Inc USA, February 1997.

[33] Norman E. Fenton and S. L. Pfleeger, Software Metrics: Course Technology, June 1998.

[34] - 4A] C. Consortium, "Poor Project Management Problem of E-Projects", Cutter Consortium: The Cutter Edge, November 2000.

[35] J. Offutt, "Quality Attributes of Web Software Applications", Software, IEEE, vol. 19, May 2002 pp 25-32.

[36] - J. Offutt, "Quality Attributes of Web Software Applications", Software, IEEE,vol. 19, May 2002, pp 2532.

[37] - G. Brajnik, "Towards Valid Quality Models for Websites", in 7th Conference on Human Factors and the Web, Madison, Wisconsin, June 2001

[38] - Fogg B.J., Marshall J., Laraki O., Osipovich, A. Varma, C. Fang, N. Paul, J. Rangnekar, A. Shon, J. Swani, P. and Treinen M (2001), What makes Web sites creditble? A report on a large quantative study, Proceddings of CHI'01, Human Factors in Computing Systems, 61-68. 